Please do not remove this page

RMIT

UNIVERSITY

\title{
Interpreter linguistic intervention in the strategies employed by police in investigative interviews
}

Lai, Miranda; Mulayim, Sedat

https://researchrepository.rmit.edu.au/esploro/outputs/9921861947101341/filesAndLinks?institution=61RMIT_INST\&index=null

Lai, M., \& Mulayim, S. (2014). Interpreter linguistic intervention in the strategies employed by police in investigative interviews. Police Practice and Research: An International Journal, 15(4), 307-321.

https://doi.org/10.1080/15614263.2013.809929

Document Version: Accepted Manuscript

Published Version: https://doi.org/10.1080/15614263.2013.809929

Repository homepage: https://researchrepository.rmit.edu.au

(C) 2013 Copyright Taylor and Francis Group, LLC.

Downloaded On 2023/04/26 19:48:38 +1000

Please do not remove this page 
Thank you for downloading this document from the RMIT Research Repository.

The RMIT Research Repository is an open access database showcasing the research outputs of RMIT University researchers.

RMIT Research Repository: http://researchbank.rmit.edu.au/

\section{Citation:}

Lai, M and Mulayim, S 2013, '(In Press) Interpreter linguistic intervention in the strategies employed by police in investigative interviews', Police Practice and Research: An International Journal.

See this record in the RMIT Research Repository at:

https://researchbank.rmit.edu.au/view/rmit:21947

Version: Accepted Manuscript

Copyright Statement: (c) 2013 Copyright Taylor and Francis Group, LLC

Link to Published Version:

http://dx.doi.org/10.1080/15614263.2013.809929

PLEASE DO NOT REMOVE THIS PAGE 


\section{Interpreter linguistic intervention in the strategies employed by police in investigative} interviews

Miranda Lai* and Sedat Mulayim

Translating and Interpreting Discipline, Royal Melbourne Institute of Technology (RMIT), Melbourne, Australia

Police interviews are high-stakes activities that bear legal consequences when the cases move to court proceedings. A wide range of literature exists on police interviewing strategies aiming to obtain complete information from the interviewee, however this literature focuses primarily on monolingual settings only. This paper reports on an empirical study examining the word choices made by interpreters of eleven selected languages in 3 scripted police interview excerpts. The study found that considered verbal strategies deliberately employed by police in investigative interviewing may be interfered with by the interpreter in a bilingual setting. The authors discuss the implications of such linguistic intervention for police interview outcomes and propose improvements for the training of interpreters and police.

Keywords: investigative interviewing; police interpreting; bilingual police interview; interpreter linguistic intervention; meaning-based interpreting; form-based interpreting

\footnotetext{
* Corresponding author. Email: miranda.lai@rmit.edu.au
} 


\section{Introduction}

Through an empirical study, the authors seek to demonstrate how inadvertent word choices by interpreters, using strategies available to them under the constant pressure to perform in realtime, may impact on questioning techniques formulated strategically by the police. Interpreting outcomes may have far-reaching implications beyond the police interviewing room, once the case being investigated moves into criminal proceedings in the legal system.

The authors commence the paper with an overview of the importance of police interviewing and the societal context in which interpreted police interviews take place. The role of the interpreter in a bilingual setting, their cognitive processes during performance, and the crosslingual transferring strategies they employ, is then explained. The empirical study is introduced in the following section. In this study a number of interpreters were required to interpret specially selected excerpts of police interviewing questions in laboratory settings. This section is followed by an analysis of the findings, and discussions on ways to mitigate the impact of interpreter linguistic intervention on police interviewing outcomes.

Although over the last few decades significant advancement has been achieved respectively in theoretical and empirical research into best-practice police interviewing and in interpreting performance analysis, there has been little evidence of cross-pollination between these two fields. Through this paper, the authors wish to bring to the attention of both the police and the interpreting profession the fact that language mediation is now required more frequently in police investigative interviewing. The findings of this study will add to the argument that closer 
collaboration between the two professions is vital to their operations in an increasingly linguistically diverse world.

\section{Overview of the police investigative interview}

The role of investigative interviewing in criminal justice

Investigative interviewing is one of the most common and important law enforcement activities within a criminal justice system (McGurk, Carr, \& McGurk, 1993; Milne \& Bull, 2006). The outcomes of investigative interviewing have significant implications for society. As Milne and Bull (1999, p. 191) aptly put it: "Poor interviewing is of no value to anyone; it is a waste of time, resources and money. No one wins. People will not come forward if they have no confidence in the quality of investigators' interviewing techniques."

While the police officer's competence in investigative interviewing is critical in criminal investigation, even the most skilful police officers have to depend on language interpreting when they are unable to communicate with an interviewee who does not understand, or has problems expressing himself / herself in the language the police officer uses. How the interpreter renders the utterances by the interviewer and the interviewee becomes an extra factor impacting on the success or otherwise of the interview. This is an area that appears to be underresearched and which warrants special attention. 
The role of the interpreter in investigative interviewing

Interpreters have been given many labels, from the jurisprudential perspective of 'a phonograph...a transmission belt...a bilingual transmitter' (Morris, 1999, p. 8), an 'electric transformer' (Wells 1991, as cited in Gibbons, 2003, p. 247), 'conduit of communication' (Laster, 1990, p. 18; Laster \& Taylor, 1994, p. 112; Russell, 2002, p. 117), a 'cipher', 'medium of communication' and a 'language machine' (Roberts-Smith, 2009, p. 14), to popular metaphors such as a 'black box' (Westermeyer, 1990, p. 747) or a 'cultural mediator' (Katan, 1999, p. 12; Jalbert, 1998, as cited in Leanza, 2007, p. 14). A less flattering description of the court interpreter is afforded by Morris (1999, p. 7) 'a piece of gum on the bottom of a shoe ignored for all practical purposes, but almost impossible to remove', otherwise known as the 'Gum Syndrome’.

No matter how the interpreter's role is described, the core competence of an interpreter is ultimately instant comprehension of contextualised meaning in one language and expression of the totality of the message in the other language. Emphasis must be put on 'instant', which refers to the spontaneity of the action, and 'contextualised', which refers to changes in meaning depending on the context or setting in which an utterance is produced. This means instant decision-making on the part of the interpreter in order to achieve smooth communication between the conversing parties.

Some scholars from the interpreting discipline, through their quantitative and qualitative research, point to the reality that the interpreter's role in a communicative event is more complex, thus more prominent or 'visible' (Angelelli, 2004; Merlini \& Favaron, 2003; Morris, 
1999; Niska, 1995) than is perceived by users of the interpreting service, or even the interpreters themselves. This is in contrast to the traditional view held by the legal fraternity, who prefer interpreters to be as 'invisible' as possible (Laster \& Taylor, 1994; Nakane, 2009; Roy, 2000), a view stemming from the legal profession's suspicion of interpreters who may usurp the judicial function of 'interpreting' the law (Morris, 1995, p. 25-26). This attitude is manifested in the courtroom where a common admonition is not to interpret but to translate, a term which is defined, sometimes expressly and sometimes by implication, as rendering the speaker's words verbatim (ibid). Hale and Gibbons (1999, p. 207), therefore, contend that 'although interpreters are essential in bilingual cases, they are not particularly liked by anyone in the courtroom. They are always seen as a necessary evil that is tolerated rather than welcomed'.

Police discourse is regarded by Coulthard and Johnson (2007, p.40) as a legal sub-genre. Gibbons (2003, p. 186) also observes that legal language is not only used by lawyers, but also by police in certain circumstances. A range of linguistic strategies are available to the interviewing police officer, who may use coercive questions or leading questions to exert a high level of control through 'peaceful, persuasive means' (Hale, 2007, p.71) to establish rapport, and sometimes to 'co-construct the discourse collaboratively' (ibid) with the interviewee in order to ultimately solicit a confession. Police interviews are produced to be overheard (Heydon, 2005, p. 39) in the sense that 'their first target audience is the courts - lawyers and judges', and 'the other target audience is the people who are interviewed.' (Gibbons, 2003, p. 186). Laster (1990, p.25) argues that:

$[\mathrm{t}]$ he linguistic tricks employed by police in an interview are probably not dissimilar from those employed in courtroom cross-examination. But because police interviews are 
conducted in private, there is no 'umpire' to ensure that the questioner remains within accepted procedural parameters, and there is the implicit and sometimes explicit possibility of coercion of various sorts to enlist the cooperation of the non-English speaker.

Due to this absence of an 'umpire', Laster and Taylor (1994, p.136) therefore are of the view that for those who are linguistically disadvantaged, 'the right to have an interpreter during police questioning is probably more significant than the right to an interpreter in court proceedings'.

An appreciation of the interpreter's internal cognitive processes and external linguistic behaviour by the police interviewer and the broader legal profession, including the lawyers and judges, will be beneficial in forming reasonable expectations in bilingual communication facilitated by interpreters. It can also help to achieve the best possible communicative outcomes that are ultimately fair and just to all involved. After all, Roy $(2000$, p. 63) reminds us that in an interpreted triadic communicative event 'all parties involved are jointly responsible, to differing degrees, for its communicative success or failure'.

\section{The process of interpreting}

Users of interpreting services should appreciate that interpreting is 'language performance under real time constraint' (Gibbons, 2003, p. 246). Interpreted communication, by its nature, takes twice as much time. Interruptions for clarification initiated by interpreters in the courtroom are sometimes frowned upon by judges or lawyers, because they will further lengthen the proceedings, adding much pressure to the interpreters' performance (Hale \& Gibbons, 1999, p. 207). Lack of access to case briefs further adds to the adverse factors 
affecting interpreters' performance. In Australia, for example, publicly funded interpreters are booked to attend court proceedings with only minimal information, such as which court to attend (e.g. Magistrate's Court, Family Court, or a certain tribunal), case number, LOTE speaker's name (this may be the defendant or the witness), or police prosecutor's name. No meaningful preparation for the assignment can be done because information about the nature and history of the case is not made available to them under the current system. Thus, interpreters end up being the least informed in the courtroom, among the judge, the prosecutor, the solicitors, and the defence barrister and jury if there is one. Considering that it is the interpreter who bears the responsibility for making a bilingual courtroom proceeding work, and the complex nature of the law, it is debatable how even an interpreter of the highest calibre is able to perform to the best possible level for all parties concerned. It is therefore no wonder Hale and Gibbons (1999, p. 207) contend that 'full legal exactitude is probably not feasible'.

Existing literature on legal interpreting largely concentrates on the courtroom setting (Hale, 2007, p. 90) due to the comparative accessibility of court trials and transcripts to, for example, interpreter-assisted police interviews which are held close-door. O'Barr $(1982$, p. 1) states that in courtroom discourse 'how something is said may be more important than what is actually said'. In this light Hale asserts that interpretation accuracy in the courtroom involves more than simply relaying the content of the utterance; it also involves 'how' the utterance is expressed (2007, p. 90-97). A simple example below demonstrates how the same meaning can be expressed differently, revealing completely different speaker attitudes and states-of-mind:

1. Could I have your full name please?

2. Tell me your full name, will you? 
One would be extremely concerned if these two utterances were interpreted the same into the other language. Of course, interpreting across languages is often much more complicated than this. In any case, it is very important to express meaning as well as conveying the speaker's intention, tone, attitude etc. These so-called extra-linguistic features are an integral part of communication between two conversing parties in any setting. In a high-stakes courtroom trial, interpreting only the content of an utterance, but not how the utterance is made, puts witnesses at risk of being judged based on the interpreter's style rather than their own (Hale, 2007, p. 9497). Forensic linguist William O'Barr (1982, p.1) argues that people do not realise how important the 'form' really is, reminding us that how utterances are expressed is just as important as what is said.

If we accept police discourse as a 'legal sub-genre' (Coulthard \& Johnson, 2007, p. 40) and the fact that police interviews are an 'upstream' activity in the criminal investigation process (Cotterill 2002, p. 111), we posit that, like courtroom interpreting, much of police interpreting is done primarily conveying the meaning of utterances, but lack attention to 'how' utterances are expressed

\section{Strategies for legal interpreting}

Interpreters deal with 'meaning' all the time. Mona Baker (2011) identifies four levels of meaning:

1. Propositional meaning (real-life meaning), eg. hit, beat, eat, walk, complain.

2. Expressive meaning (propositional meaning plus speaker's feelings), eg. bash, gobble, jog, dob in. 
3. Presupposed meaning (words or expressions occurring together - collocations), eg. take for granted, look up a word, brush teeth, breach a code of ethics.

4. Evoked meaning (dialect and register: geographic, temporal, social), eg. teeth pop out/erupt (children).

It is unlikely that each of these levels would have exact equivalents, even in languages with similar cultural backgrounds. This demonstrates the complexity of interpreting between two languages and cultures. It should also be pointed out that meaning does not always appear in one constant form. Different forms of meaning may arise as a result of different factors, such as who the speakers are, the setting in which an utterance is made and the time of utterance.

As discussed earlier in the article, the legal profession has a suspicion that interpreters may usurp the judicial function of 'interpreting' the law. This attitude transpires into common instructions to court interpreters 'not to interpret but to translate', a term which morphed to mean rendering the speaker's words verbatim (Morris, 1995, p. 25-26). On closer scrutiny, this state of affairs stems from misunderstanding the context in which the term 'interpreting' is used. It may be helpful to introduce the Russian-born American linguist Roman Jakobson's (1959) description of three kinds of translation (note here translation is used in its broad sense to include both the written form and oral form):

1. Intralingual translation or rewording, is an interpretation of verbal signs by means of other signs of the language, eg. to jaywalk is to cross the street illegally or in a reckless manner (using words to explain what jaywalk is in the same English language) ;

2. Interlingual translation or translation proper, is an interpretation of verbal signs by means of signs of some other language, eg. bon voyage in French is translated as 'have a good trip' into English; 
3. Intersemiotic translation or transmutation, is an interpretation of verbal signs by means of signs of nonverbal sign systems, eg. instead of telling people smoking is prohibited in a venue, a round sign is displayed with an image of cigarette in the middle and a diagonal line across.

It is apparent that what the judiciary referred to as 'interpreting' the law is a kind of intralingual linguistic operation, i.e. within the same language. What interpreters do, in fact, is a kind of interlingual linguistic operation, i.e. across different languages. It seems someone at some point in time confused the two different linguistic operations, hence created the myth about the verbatim requirement for court interpreters. Mikkelson (1999) confirms that 'there is nothing in the literature on translation theory, or even in statutes and rules of court governing interpreting [in the USA], that requires a literal or word-for-word translation.' She contends that it is high time that judges and lawyers stop instructing interpreters to 'not interpret, just translate everything literally.' She also encourages interpreters to not be afraid 'to use common sense and good judgment in determining how to render the language of the courtroom ... in an efficient and intelligible manner, while retaining all elements of meaning and style.'

González et al. (1991, p 16-17) note that in the courtroom environment, 'the form and style of the message are regarded as equally important elements of meaning', and the interpreter must 'mediate between these two extremes: the verbatim requirement of the legal record and the need to convey a meaningful message in the target language.' If we use a continuum as shown in Diagram 1 with 'form-based' on the one end and 'meaning-based' on the other to represent the two extremes of interpreting strategies an interpreter can adopt, we can illustrate that 
interpreting in various contexts invariably falls at a certain point on the continuum. For example, interpreting between a welfare worker and a LOTE (Language Other than English) speaking client will more likely fall towards the meaning-based end of the continuum, denoting a higher level of free translation or sense-for-sense translation, whereas legal interpreting will more likely be situated somewhere nearer to the form-based end where a higher level of literal or word-for-word strategy is adopted to preserve the pragmatic aspects of the utterances. González et al. (1999, p. 17) suggest the following for interpreters in a courtroom setting:

... conceptual units ... must be conserved, not word-by-word, but concept-by-concept. To be true to the global Source Language message, paralinguistic elements such as hesitations, false starts, hedges, and repetitions must be conserved in a verbatim style and inserted in the corresponding points of the Target Language message.

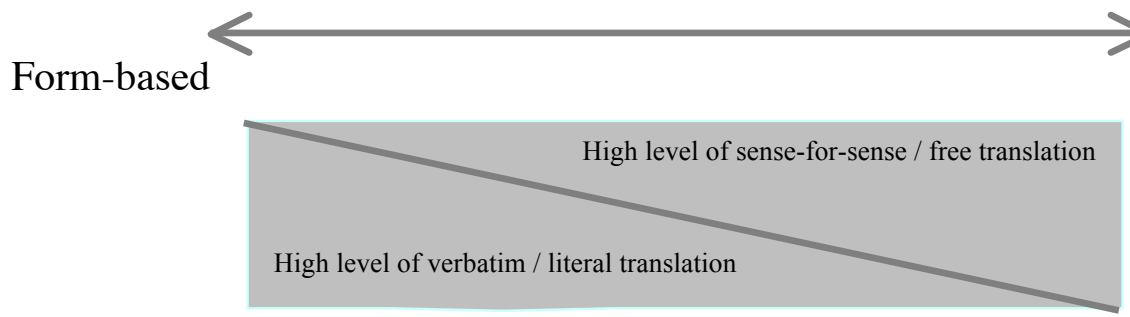

Diagram 1: Interpreting Strategy Continuum.

Studies on interpreters' intuitive choice of interpreting strategies are few and far between. Psycholinguists Fabbro and Gran's (1994, p. 304) research on student and professional simultaneous interpreters ${ }^{1}$ shows that student interpreters tend to opt for word-for-word

\footnotetext{
${ }^{1}$ Internationally the modality of interpreting is divided into two broad categories in relation to the timing when the output utterances are produced. In simultaneous interpreting, the interpreter listens and speaks at the same time
} 
translation, whereas professional interpreters adopt a more meaning-based interpreting strategy. Danish researcher Helle Dam's empirical studies on consecutive interpreting ${ }^{2}$ (1998) and simultaneous interpreting (2000) point to the fact that form-based interpreting, i.e. the word-forword or literal approach, predominates over the meaning-based approach, and that the formbased strategy is more usually associated with a less difficult source message, whereas the meaning-based approach is linked to more difficult text. The 'more difficult text' in Dam's 2000 study includes more specialised terms and numbers, longer sentences and clauses, and higher rates of speech. Such design of research instruments conforms with the general literature of interpreting, in which names, numbers, enumerations, fast speech, strong foreign or regional accents, poor speech logic, poor sound etc. are often characterised as sources of interpreting difficulties or problem triggers (Seleskovitch 1975; Gile 1995, p. 172-174; Gile 2009, p. 176) that increase the interpreter's required cognitive processing capacity and, consequently, result in deteriorated interpreting performance. Drawing from the outcome of these studies, it appears that when faced with source text difficulties:

[t]he interpreters would therefore be less able to base their target text on source text form, even if they wished to do so, but would have to rely primarily on source text meaning. In other words, interpreters may tend to reformulate, rather than to reproduce. (Dam, 2000, p. 52)

Applying this in a police interview setting, where the interpreter is confronted with the above-mentioned problem triggers, on top of a general lack of familiarity with the overall

most of the time. In contrast, in consecutive interpreting, the interpreter alternates between listening and speaking (Gile 2009). In the context of courtroom examination-in-chief and cross-examination, or in police interview settings, interpreting is normally done consecutively.

${ }^{2}$ See footnote 1 . 
context and content of the narratives afforded by the interviewee, it then becomes counterintuitive for the interpreter to have to adopt a more form-based interpreting strategy. It also becomes a cognitively more demanding task if the interpreter were to follow González et al.'s recommendation to render the source utterances 'concept-by-concept' (in other words, a more meaning-based approach) while at the same time accommodating the form-based approach by inserting other paralinguistic elements in the interpretation, eg. the uhm's and ah's, hesitations, hedges etc.. These studies and their implications, therefore, point to a possible need for specialised training of interpreters working in specifically legal and police settings in order to accommodate requirements of their performance that are counterintuitive and more 'artificial'.

Verbal strategies employed by police

There is a growing consensus among police practitioners and researchers that investigative interviewing skills are not innate but acquired. Such skills must be nurtured and developed through training that is firmly based upon empirical research (Baldwin 1993; Pearse and Gudjonsson 1996; Clarke and Milne 2001; Bull and Milne 2004). Guidelines are drawn and training is provided to cover the behavioural and linguistic aspects to make interviewing more efficient and effective. Therefore the verbal strategies employed by the interviewing police officer are not a random selection of words or styles. For example, when dealing with children, questions like 'Can you describe to/for me?' were found to elicit more substantive responses, whereas questions like 'Do you know?' or 'Can you remember?' were less likely to do so 
(Heydon, 2005, p. 162). Thames Valley Police (English) training material recommends the use of TED to encourage interviewee to give longer answers:

Tell me.....

I'd like you to explain....

Can you describe.... (Schollum, 2005, p. 55)

New Zealand Police 2004 guidelines also recommend the use of 'How come' questions instead of 'Why' questions when dealing with children and vulnerable witnesses because it is less accusatory.

It is therefore of the utmost importance that the interpreter in these situations is fully aware of the police verbal strategies and renders them in a meaningful way as well as preserving the 'form' to accomplish what the police want to achieve in the questioning.

\section{The Study}

\section{Research methodology}

This is an empirical study designed to simulate bilingual police interviewing mediated by interpreters. The research tool is a mock first-contact police interview using a scenario from the researchers' real-life professional experience. It contains three excerpts, as listed below, from a complete interview between an interviewing police officer and a suspect of crime, incorporating 
the police caution ${ }^{3}$, TED questions, and two 'how come' questions as marked in bold and italics.

Scenario: This is part of an interview between a shoplifting suspect who is a vulnerable person (child or adult with impairments or disabilities). The person is suspected of shoplifting as s/he left a local jewellery shop with a gold ring and bracelet without paying. S/he was stopped by the security guard outside the shop and the police were called. The interview commences at the police station where the police officer administers the police caution and then asks several questions about the incident in an audio-recorded interview.

\section{Excerpt 1:}

$(\mathrm{ST}=$ Source Text $)$

ST I intend to interview you in relation to the offence of shoplifting. You do not have to say or do anything but anything you say or do may be used in evidence. (pause)

You may communicate or attempt to communicate with a legal practitioner.

ST You may communicate or attempt to communicate with a friend or relative to tell them about your whereabouts.

ST You may be charged with the offence of shoplifting.

\section{Excerpt 2:}

\footnotetext{
${ }^{3}$ Equivalent of the Miranda Warning in the USA.
} 
ST At 3pm today, you were observed leaving the jewellery shop. How come you failed to pay for the items you picked up at the store?

ST How come you placed the gold ring in your bag but not the other items when you were approaching the check-out?

ST The items add up to \$247. I would like you to explain to me how you intended to pay for the items as you only had $\$ 8$ with you.

\section{Excerpt 3:}

ST Can you describe how you were treated by the shop security staff when they stopped you?

ST Tell me what your health situation is?

ST I need a copy of your medical reports. Can you please bring them at your earliest convenience?

The research sets out to test the hypothesis that professional interpreters not aware of specific wording in police questioning tend to employ a more meaning-based approach in their interpretation. Eleven currently practicing professional interpreters of various community languages, who were also engaged in teaching in the RMIT interpreting programs at the time of research (March 2011), were recruited and asked to interpret the excerpts into their own languages. None of these interpreters had received any specific training in police questioning techniques, although their professional interpreting experience ranged from 2 years to over 10 years. . The eleven languages include Arabic, Japanese, Haka Chin, Italian, Korean, Malay, Mandarin, Pushto, Spanish, Turkish and Vietnamese. The interpreters were not told about the specific wording incorporated into the excerpts, but were briefed on the scenario of the mock 
police interview and asked to interpret as in a real-life police interview assignment. The research instrument was audio recorded in digital format at a normal speech rate (approximately 90 words per minute; by a native English speaker) to simulate a real-life situation, and played to individual interpreters in an interpreting laboratory on a computer. The interpreters' renditions of these police questions into their respective languages were digitally recorded in the laboratory. Another eleven independent professional interpreters in these languages were separately recruited and asked to transcribe the interpreted excerpts, without access to the original English script, and to back-translate them into English for the researchers to conduct microanalysis. Unstructured interviews were subsequently conducted with the first eleven interpreters who rendered the interpretations, to clarify issues the researchers identified in their analysis and to get the interpreters' views on the nature of linguistic changes that were identified by the back-translation process. The collection of data (recorded renditions, transcriptions and back-translations) was completed in the month of March 2011.

\section{Findings of the Study}

Analysis of the rendering of the 11 languages at the micro level found that the specific recommended wording incorporated in the research tool was largely conveyed by the interpreters. Words used to convey their primary or propositional meaning (Baker, 2011) such as 'Tell', 'Explain' and 'Describe' in the TED questions appeared to have consistently been transferred into the target languages accurately in terms of meaning and form. The communicative intent of using these words in an investigative interview has, therefore, largely been preserved. This outcome seems to conform with Newmark's $(1988$, p. 48) observation 
that 'the more universal the text, the more a broad equivalent effect is possible because the original idea is out of cultural frontier', in other words, less cultural-bound. However, with respect to questions where words were not used in their primary meaning, such as 'come' in 'how come', or when the expression is an idiom such as 'at your earliest convenience', the degree of precision in conveying both the meaning and form as intended by the investigative interviewing strategies seemed to be more divergent.

The interpreter's involvement in a bilingual investigative interview, by Jakobson's (1959) definition, falls in the 'interlingual translation' which by default constitutes a kind of linguistic intervention as the communication must be 'routed' through the interpreter in order to make the interview work. As opposed to a monolingual interview, in which communication takes place directly between the two conversing parties, in a bilingual interview at any given time there is one person who does not understand what is being said (Bot, 2005). In particular, in the context of police investigative interviewing, where the product of the interview (e.g. transcript of the interview or a witness statement) is likely to be used as evidence in a court of law, this linguistic intervention performed by the interpreter needs to be properly managed and contained in such a way that the only difference, when compared with a monolingual interview, should concern the triadic flow of information. Everything else (the form and the content of the information) should be maintained as closely as possible in the other language as if the interview were conducted between two parties who spoke the same language.

In terms of the ways the eleven interpreters handled the two 'How come' questions, they can be categorized in three groups: 
Group 1: four interpreters (Japanese, Mandarin, Turkish, Vietnamese) opted for the meaningbased approach, so the interpretation in both occasions was rendered as the more accusatory 'why'.

Group 2: another four interpreters (Arabic, Italian, Korean, Spanish) rendered once using the meaning-based approach, i.e. the interpretation became the more accusatory 'why', and once using the form-based approach, i.e. the interpretation was the 'how come' equivalent in their respective languages.

Group 3: the last three interpreters (Haka Chin, Malay, Pushto) opted for the form-based approach, so the interpretation in both occasions was rendered using a similar expression meaning 'how come' in their respective languages.

In the total of 22 occasions (two 'How come' questions in the research tool $\mathrm{x} 11$ languages $=22$ occasions), meaning-based rendering accounted for almost 55\% (2 occasions $\mathrm{x} 4$ languages from Group $1+1$ occasion x 4 languages from Group $2=12$ occasions; 12 out of 22 occasions $=54.5 \%$.

This outcome must be examined a little further to ascertain if the linguistic intervention was justified or unjustified. Unstructured interviews with the eleven interpreters who rendered the interpretation of the research tool revealed that all 11 languages are capable of producing a linguistic equivalent, or a similar one, to express the less accusatory, more colloquial 'how come' question, as distinct from the more accusatory, less informal 'why' question. An interesting twist must be pointed out though about Pushto, in which the linguistic equivalent of 
'how come' actually carries a harsher and more accusatory connotation than the 'why' form of the question.

In linguistic operations across languages within the police interviewing context this paper is confined to, the researchers are of the view that where the same linguistic alternative, in both form and meaning, is available in the target language, the interpreter should strive to convey both, necessitating the use of a more form-oriented interpreting approach (closer to the formbased end of the Interpreting Strategy Continuum in Diagram 1). Straying too far away from this end, knowingly or unknowingly on the interpreter's part, would result in what the researchers call 'unjustified linguistic intervention' such as in all of the cases in Group 1 and half of the cases in Group 2. On the contrary, in the case where a linguistic equivalent of an expression in the target language is not readily available in the same form, the interpreter could then exercise what the researchers call 'justified linguistic intervention' to at least convey the primary intention of the utterance in order to achieve the aim of communication. This approach is closer to the meaning-based end of the Interpreting Strategy Continuum in Diagram 1. Admittedly this approach is the second best, but under the circumstances, the only option.

In the special case of the Pushto language in this research, it serves as a reminder that pragmatic functions of language cannot be taken for granted when interlingual operations are involved. In this research, the Pushto interpreter opted for a form-based approach in the interpretation, being aware of the availability of such an equivalent in the target language. Supposedly this would be the preferred approach based on the above analysis for the other ten languages. However adhering to the form in this case actually achieved the opposite effect (i.e. 
sounding more accusatory) to the intention of the original question in English (i.e. trying to build rapport and be less accusatory).

\section{Implications of the current Study}

\section{Limitations of the research}

This small-scale empirical study used artificially scripted police questions incorporating specific wording recommended by best police investigative interviewing practice. The sample size was limited to 11 languages popular in communities around Melbourne, Australia, by one interpreter each. The following three aspects identified by this research need to be further explored and corroborated with a larger population.

Firstly, although the findings do not confirm conclusively the research hypothesis that professional interpreters not aware of specific wording in police questioning tend to employ a more meaning-based approach in their interpretation (approximately 55\% in the corpus opted for the meaning-based approach), it reveals a relatively high level of form-based approach (45\% versus 55\%) knowingly or unknowingly adopted by the interpreters. From the police point of view, this outcome can be construed as $55 \%$ chance of their verbal strategy being thwarted by the interpretation, i.e. their deliberate choice of wording with an aim to build rapport and reduce the level of accusation may end up sounding more formal and accusatory. In Australia, there is no specialised interpreter training that touches on police interviewing strategy, yet making available such training is the only way to address this issue. 
Secondly, the research points to the fact that, in the police questioning context, words used in their primary or propositional meaning achieve a more homogeneous outcome in the sense of a faithful transfer into the target language, whereas words not used in their primary sense could yield more divergent outcomes where a tug-of-war between the two ends of the Interpreting Strategy Continuum in Diagram 1 may take place. This is because languages have more in common at the propositional meaning level (eg, eat, drink, walk, tell, look) but differ significantly at the expressive meaning level (eg, gobble, imbibe, jog, mumble, glance). Although this assertion needs to be validated by a much larger research corpus, it may be worthwhile for the police to take it into account when formulating their verbal strategies in their interviewing practice.

Thirdly, interpreters must be particularly mindful of the linguistic interventions they perform in the police interviewing settings. Where there are no linguistic options in both form and meaning, they can justifiably provide a second-best choice by opting for a meaning-based alternative. However, where possible, they should strive to render a linguistic unit to reflect both the form and meaning in order to preserve the communicative intent afforded by the police interviewer in order to minimise 'unjustified linguistic intervention'. Again, if the police can accommodate these interlingual operational issues by consulting relevant experts, and conduct research prior to formulating their recommended verbal strategy, it would minimise the interpreter's chance of engaging in unjustified linguistic intervention. The importance of seeking interlingual consultation is further highlighted when we consider the unusual case of the Pushto language in the reverse pragmatic functions in this research. 


\section{Implications for practice}

Although the results of the research are not statistically significant enough to confirm the hypothesis, it does reveal a slight inclination towards the meaning-based approach employed, consciously or unconsciously, by the research subjects. This in turn leads to justified or unjustified linguistic intervention in correspondence to the absence or existence of linguistic equivalent in both form and meaning in the target language. In other community interpreting settings where the communicative intent is mostly to fulfil the provision of public service, e.g. a meeting between a teacher and a parent, or a social welfare worker with a client, adopting a meaning-based approach by the interpreter would serve the purpose of facilitating the communication in question. However, given the fact that wording chosen by police questioning is not arbitrary, the interpreter's lack of awareness of such verbal strategies may result in them unknowingly engaging in unjustified linguistic intervention, thus obstructing the intended interviewing outcome.

Since interpreter training became available in Australia in the 1970s, it has been delivered in a generalist approach guided by the National Accreditation Authority for Translators and Interpreters (NAATI) (Hale, 2007). All interpreting courses in Australia are therefore generic (ibid), covering all domains that a community interpreter might work in, e.g. education, immigration, legal, medical, social welfare, etc. More than three decades on, as interpreting and translating has come of age and become a discrete discipline in its own right, specialised training in various domains needs to be introduced. In the context of this paper and from the study analysis so far, there is little doubt that interpreters must develop an awareness of verbal 
strategies used in police questioning practice. Failure to recreate word choices or sentence structures in the target language, where there are linguistic resources to do so, would have significant consequences to all parties involved.

From the point of view of police interviewers, it is fair to say that various state police forces in Australia have made significant progress in raising their members' awareness of the importance of engaging publicly funded professional interpreter services when faced with language barriers (McMillan, 2009). This is evidenced by Police Standing Orders in all Australian states, which mandate the use of professional interpreters (Ozolins, 2009). However this is also where the awareness stops. Other issues, such as how to work collaboratively with interpreters during interviews and the notion of involving interlingual consultancy when developing verbal strategies in investigative interviewing, are yet to be taken up by the police forces. To achieve best possible investigative outcomes in multicultural and multilingual Australia, it is high time to forge collaboration between academia and trainers from both the interpreting discipline and the police institutions.

\section{Conclusion}

Parallel to the assertion that police discourse being a sub-genre of legal discourse (Coulthard \& Johnson, 2007), police interpreting can be regarded as a sub-genre of legal interpreting. Literature and empirical studies in the field of forensic linguistics have established that form and style are as important as meaning, if not more so. Given that the products of police interpreting may constitute important pieces of evidence in the court of law, interpreters must 
strive to render both form and content in bilingual police interviews to preserve the communicative intent as completely as possible. To sensitise professional interpreters to discern justified and unjustified linguistic intervention, and to preserve as much as possible police verbal strategies in their interviews, the authors strongly advocate the need for specialised police interpreter training. To this end, collaboration between academia and trainers from both the police and the interpreting profession must be forged to ensure that when police develop their verbal strategies in investigative interviewing, due consideration is given to bilingual settings. By the same token, interpreter training must move towards specialisation, for only when interpreters are trained in police strategic interviewing will they be able to both minimise unjustified linguistic intervention and facilitate the communication in a manner as close to a monolingual setting as possible.

The authors hope that the findings of this study, and the subsequent analysis, have added to the argument that closer collaboration between the two professions is vital to their operations in an increasingly linguistically diverse world, and that continual professional cross-pollination is desirable for a just criminal system that is involved more and more in serving multi-lingual citizenry. 


\section{Note on contributors}

Sedat Mulayim is the Discipline Head of the Translating and Interpreting program at RMIT University. He has practiced as a professional interpreter and translator for more than 20 years and has extensive experience in legal and police interpreting. He is currently completing a doctoral degree in community interpreting and translation with special emphasis on institutional knowledge transfer.

Miranda Lai is accredited as an interpreter by Australia's National Accreditation Authority for Translators and Interpreters. She has many years experience as a freelance interpreter and translator. She is currently a full-time trainer and lecturer at RMIT University, and is also undertaking $\mathrm{PhD}$ research in police interpreting.

\section{References}

Angelelli, C. V. (2004). Medical Interpreting and Cross-Cultural Communication. Cambridge: Cambridge University Press.

Baker, M. (2011). In other words - a coursebook on translation (2nd ed.). Abingdon and New York: Routledge.

Baldwin, J. (1993). Police interview techniques: Establishing truth or proof? British Journal of Criminology, 33, 325-352.

Bot, H. (2005). Dialogue Interpreting in Mental Health. Amsterdam \& New York: Rodopi.

Bull, R.\& Milne, R. (2004). Attempts to improve police interviewing of suspects. In G.D. Lassier (Ed.). Interrogations, confessions and entrapment, 82-196. New York, NY: Kluwer Academic Publishers.

Clarke, C. \&. Milne, R. (2001). National evaluation of the PEACE investigative interviewing course. Police Research Award Scheme. London: Home Office.

Cotterill, J. (2002). Language in the Legal Process. Hampshire \& New York: Palgrave Macmillan.

Coulthard, M., \& Johnson, A. (2007). An Introduction to Forensic Linguistics: Language in Evidence. New York: Routledge. 
Dam, H.V. (1998). Lexical similarity vs lexical dissimilarity in consecutive interpreting: a product-oriented study on form-based vs meaning-based interpreting. The Translator, $4(1), 49-68$.

Dam, H.V. (2000). On the option between form-based and meaning-based interpreting: the effect of source text difficulty on lexical target text form in simultaneous interpreting. In B. Englund Dimitrova (Ed.), Översättning och tolkning. Rapport från ASLA:s höstsymposium, Stockholm, 5-6 November 1998 (pp. 51-81). Uppsala: Ekonomikum.

Fabbro, F. \& Gran, L. (1994). Neurological and neuropsychological aspects of polyglossia and simultaneous interpretation. In S. Lambert \& B. Moser-Mercer (Eds.), Bridging the gap: empirical research on interpretation (pp. 273-317). Amsterdam: John Benjamins.

Gibbons, J. (2003). Forensic Linguistics: An Introduction to Language in the Justice System. Oxford: Blackwell.

Gile, D. (1995). Basic concepts and models for interpreter and translator training. Amsterdam and Philadelphia: John Benjamins.

Gile, D. (1997). Conference interpreitng as a cognitive management problem. In J.H. Danks, G.M. Shreve, S.B. Fountain and M.K. McBeath (Eds.), Cognitive Precoesses in Translation and Interpreting (pp. 196-214). Thousand Oaks, London \& New Delhi: Sage Publications.

Gile, D. (2009). Basic concepts and models for interpreter and translator training. Amsterdam and Philadelphia, PA: John Benjamins.

González, R. D., Vásquez, V. F., \& Mikkelson, H. (1991). Fundamentals of court inptertation: theory, policy and practice. Durham, NC: Carolina Academic Press.

Gorden, R. (1998). Basic interviewing skills. Prospect Heights: Waveland Press.

Hale, S. B. (2007). Community Interpreting. Hampshire and New York: Palgrave Macmillan.

Hale, S. B. \& Gibbon, J. (1999). Varying realities patterned changes in the interpreter's representation of courtroom and external realities. Applied Linguistics, 20 (2), 203-220.

Heydon, G. (2005). The language of police interviewing: a critical analysis. New York: Palgrave Macmillan.

Jakobson, $\mathrm{R}$ (1959). On Linguistic Aspects of Translation. Retrieved from: http://www.stanford.edu/ eckert/PDF/jakobson.pdf

Katan, D. (1999). Translating cultures: an introduction for translators, interpreters and mediators. Manchester: St. Jerome.

Laster, K. (1990). Legal Interpreters: Conduits to Social Justice? Journal of Inercultural Studies, 11, 16-32.

Laster, K., \& Taylor, V. L. (1994). Interpreters and the Legal System. Sydney: The Federation Press.

Leanza, Y. (2007). Roles of community interpreters in pediatrics as seen by interpreters, physicians and researchers. In F. Pochhacker \& M. Shlesinger (Eds.), Healthcare interpreting: discourse and interaction (pp. 11-34). Amsterdam and Philadelphis: John Benjamins.

McGurk, B., Carr, J., \& McGurk, D. (1993). Investigative interviewing courses for police officers: an evaluation. (H. Office, Trans.) (Vol. Police Research Series). London: Home Office.

McMillan, J. (2009). Use of Interpreters: Australian Federal Police, Centrelink, Department of Education, Employment and Workplace Relations, Department of Immigration and Citizenship. Canberra: Commonwealth Ombudsman. 
Merlini, R., \& Favaron, R. (2003). Community Interpreting: re-conciliation through power management. The Interpreters' Newsletter, 12.

Mikkelson, H. (1999). Verbatim interpretation: an oxymoron. Retrieved from: http://www .acebo.com/papers/verbatim.htm.

Milne, R., \& Bull, R. (1999). Investigative interviewing: psychology and practice. Chichester: John Willy \& Sons.

Milne, R., \& Bull, R. (2006). Interviewing victims of crime, including children and people with intellegual disabilities. In M. R. Kebbel \& G. M. Davies (Eds.), Practical Psychology for Forensic Investigations (pp. 7-23). Chichester: Wiley.

Morris, R. (1995). The moral dilemmas of court interpreting. The Translator, 1 (1), 25-46.

Morris, R. (1999). The gum syndrome: predicaments in court interpreting. International Journal of Speech, Language and the Law, 6(1), 6-29.

Nakane, I. (2009). The myth of an 'invisible mediator': an Australian case study of EnglishJapanese police interpreting. Journal of Multidiciplinary International Studies, 6(1), 116.

Niska, H (1995). Just Interpret: Role conflicts and discourse types in court interpreting. In M. Morris (Ed.), Translation and the Law (pp. 293-316). Amsterdam and Philadelphia: John Benjamins.

NCOF. (2003). ACPO Investigative Interview Strategy: Training Curriculum. England: Centrex: National Crime and Operations Faculty.

Newmark, P. (1988). A textbook of translation. New York and London: Prentic-Hall International.

O'Barr, W. M. (1982). Linguistic evidence: language, power and strategy in the courtroom. New York and London: Academic Press.

Ozolins, U. (2009). Social Worker, The Law and Interpreters. In P. Swain \& S. Rice (Eds.), In the Shadow of Law: The Legal Context of Social Work Practice (pp. 20-35). Sydney: The Federation Press.

Pearse, J. \& Gudjonsson, G. (1996). Police interviewing techniques at two south London police stations. Psychology, Crime and and Law, 3, 63-74.

Roberts-Smith, L. (2009). Forensic Interpreting: Trial and Error. In S. B. Hale, U. Ozolins \& L. Stern (Eds.), Critical Link 5: Quality in Interpreting - A Shared Responsibility (pp. 1336). Amsterdam and Philadelphia: John Benjamins.

Roy, C. (2000). Interpreting as a discourse process. Oxford and New York: Oxford University Press.

Russell, S. (2002). 'Three's a Crowd': Shifting Dynamics in the Interpreted Interview. In J. Cotterill (Ed.), Language in the Legal Process (pp. 111-126). Hampshire and New York: Palgrave Macmillan.

Schollum, M. (2005). Investigative Interviewing: The Literature. Wellington: New Zealand Police.

Seleskovitch, D. (1975) Langage, langues et mémoire, Étude de la prise de notes en interprétation consécutive. Paris: Minard.

Shepherd, E. (2007). Investigative Interviewing: The Conversation Management Approach. Oxford \& New York: Oxford University Press.

Westermeyer, J. (1990). Working with an interpreter in psychiatric assessment and treatment. Journal of Nervous and Mental Disease, 178(12), 745-749. 